\title{
La dimensión ideológica en los cuentos del primer número de la revista Narración (1966)
}

\section{The ideological dimension in the stories of the first issue of the magazine Narracion (1966)}

\author{
Víctor Ramos Badillo \\ Universidad Nacional Federico Villarreal, Lima, Perú \\ 2014014952@unfv.edu.pe \\ ORCID: https://orcid.org/0000-0002-7767-9651
}

\section{Resumen}

En el siguiente artículo se analizarán los cuentos que componen el primer número de la revista Narración (1966), con el propósito de visualizar las problematizaciones ideológicas que trae consigo sobre la crítica marxista asumida por los miembros de la publicación. Si bien el grupo Narración puso de relieve un movimiento político-reivindicativo de las clases desfavorecidas en las páginas de su revista, en la sección dedicada a la ficción los cuentos publicados manifiestan distintas tendencias narrativas, que no se limitan a plantear una representación mecánica de la lucha de clases, sino una diferente localización del conflicto de clases y también sus implicancias simbólicas o políticas. Para este objetivo, se utilizará el concepto de ideología aplicado a la forma literaria, lo cual permitirá establecer los límites y las contradicciones que subsisten en el proceso narrativo del cuento.

Palabras clave Ideología, contradicción, cuento peruano, marxismo

\begin{abstract}
In the following article, the stories that make up the first issue of Narración magazine (1966) will be analyzed in order to visualize the ideological problematizations that it brings about the Marxist criticism assumed by the members of the magazine. Although the Narración group highlighted a political-vindictive movement from the underprivileged class in the pages of the journal, in the section destined to fiction, the published stories manifest different narrative tendencies that are not limited to posing a mechanical representation of the class struggle, but a different location of class conflict and also its symbolic or political implications. For this objective, the concept of ideology applied to the literary form will be used, which will allow to establish the limits and contradictions that subsist in the narrative process of the story.
\end{abstract}

Keywords Ideology, contradiction, peruvian story, marxism

Fecha de envío: 1/4/2021 Fecha de aceptación: 2/6/2021 


\section{Introducción}

La literatura peruana de las décadas de 1960 y 1970 es un área de estudios pendiente por analizar minuciosamente. Menciono esto no solo para referirme a la producción literaria publicada en libros, sino también aquella que circuló en el medio nacional a través de revistas y periódicos, soportes impresos que han sido relegados como objetos de estudio por la crítica literaria, en una salida un tanto pragmática ${ }^{1}$. Sin embargo, el panorama en los últimos años se vuelve un tanto optimista debido al interés por analizar revistas de la vanguardia peruana, en especial las que se publicaron fuera de Lima. Del mismo modo, la impresión de facsimilares de revistas del siglo XX peruano retoma el interés por las indagaciones sobre aquellos núcleos intelectuales que emprendieron proyectos editoriales y narrativos materializados en lo que se ha denominado como cultura impresa. Dentro de la variedad de publicaciones revisteriles, en 1966, posteriormente al auge de publicaciones de libros de los autores agrupados en la Generación del 50, surgiría una revista en particular, cuyos postulados no solamente apelaban a renovar las fórmulas estéticas que imperaban en el campo literario, sino que también lo conjugaban con elementos de orden ideológico-político. Estoy hablando de la revista Narración, organizada a partir del grupo literario del mismo nombre, aparecida en noviembre de aquel año. Su posicionamiento en el mundo literario buscó cuestionar la interpretación canónica de lo que implicaba la labor literaria, limitada al espíritu de la clase media acomodada. Para lograr esa arremetida contra el establishment intelectual, sus ejes programáticos partieron de una crítica literaria marxista, complementada por las vertientes doctrinarias del leninismo y el maoísmo. Hay que comprender que la inclusión de la teoría marxista dentro de sus postulados teóricos se entiende mejor a través de la circulación de ideas de izquierda en el Perú de los $60^{2}$. En ese sentido, si bien se puso en marcha la perspectiva marxista en el aspecto de la crítica, desde la creación literaria también implicaba tomar posición desde el terreno artístico, para permitir la consolidación de un bloque intelectual que cuestionaran las formas e interpretaciones burguesas sobre el trabajo de los escritores. Ese posicionamiento, como se podrá ver en las siguientes páginas, no necesariamente implicaba introducir explícitamente la lucha de clases dentro de los cuentos de la revista, sino que postulaba una postura un tanto problemática para pensar la relación entre teoría y práctica, puesto que los cuentos publicados en el primer número de Narración generan distintos sentidos en los lectores. Para clarificar mejor esta aparente contradicción, Roberto Reyes, miembro del grupo, nos relata lo siguiente: 
en Narración el compromiso político-ideológico no implicaba seguir los lineamientos de un determinado partido, requerimiento siempre limitante para la creación. Políticamente, el grupo funcionaba como un frente, en la medida [en] que existían varias posiciones políticas. Lo único que se esperaba de sus integrantes era un compromiso con el pueblo, con los sectores oprimidos de la sociedad; una demanda que cada uno interpretaba a su manera (2018).

Así, el agrupamiento de escritores en la revista Narración pasaba por un asumir una posición de clase, más allá de que cada uno haya o no leído a Marx. Esta adscripción ideológica evidentemente no condicionaba su práctica artística, la cual se comprueba en los abordajes ficcionales publicados en la revista. Justamente esos bordes donde se desdibujan la teoría y la práctica, que sería la sección dedicada a los cuentos, es lo que analizaré en las páginas que siguen. Si bien en años recientes se retomó el interés por esta revista a raíz de la publicación de su versión facsimilar en 2018, en el corpus de trabajos dedicados a la revista huelgan por su ausencia el análisis ideológico-político que traspiran los textos que componen cada número. Quizás el más dedicado estudio ha sido la tesis de licenciatura de Jorge Valenzuela, quien señala que Narración se identificó con las mayorías naciones y buscó la liberación de las conciencias por medio de la literatura $(1989$, p. 44). La pregunta que aquí queda pendiente es cómo sucedió ese proceso de liberación que se apunta. Una alternativa ante esto podría ser la verificación de la amplitud del contenido marxista dentro de la revista, especialmente el dedicado a la ficción, puesto que esta lleva a los límites dichos procedimientos teóricos asumidos. En ese sentido, en el siguiente artículo se busca plantear una entrada distinta al análisis de esta revista, con el propósito de visibilizar otro horizonte metodológico para el estudio. A saber: el papel ideológico que subyacía detrás de los cuentos en el primer número de la revista Narración.

\section{Sobre el concepto de ideología y su función dentro de la literatura}

Para concretar el análisis sobre la dimensión ideológica, utilizaré los postulados de los críticos anglófonos Terry Eagleton y Fredric Jameson, cuyas reflexiones teóricas se entroncan con una interpretación marxista de la literatura, de modo que podré introducirlas mejor para los fines de este artículo. En una explicación de manera general, Eagleton sostiene que

La ideología no es, en primer lugar, una serie de doctrinas; significa la manera en que los hombres encarnan sus papeles en la sociedad de 
clases, los valores, ideas e imágenes que los unen a sus funciones sociales para de esta manera impedirles un verdadero conocimiento de la sociedad en su conjunto (1978, p. 35-36).

Es decir, el papel que la ideología estaría cumpliendo es de un lente que cohesiona socialmente a los sujetos a partir de la aceptación de las reglas de juego impuestas por el modo de producción contemporáneo: el capitalista. En otras palabras, la labor de la ideología, en este sistema económico, es aceptar el fetichismo de la mercancía como unidad mínima del tejido social. Así, en cuanto se lo crítica o se lo cuestiona, se va desestabilizando su poder cohesionador. Esto no quiere decir que mediante esta operación se vaya a alcanzar una situación posideológica, donde se encuentre uno "libre" de ideología. Al contrario: esto es imposible, puesto que aquella acondiciona el modo de relacionarse socialmente. Ahora bien, las ramificaciones de la ideología no se limitan meramente a su expresión en la vida social cotidiana, sino también repercute en las producciones artísticas, donde se encuentra la ficción narrativa. Al respecto, siguiendo a Pierre Macherey, Eagleton nos explica mejor sobre la relación ideología y arte:

La ilusión —experiencia ideológica normal de los hombres- es el material sobre el que el escritor va a trabajar; pero al trabajar sobre él lo transforma en algo diferente, le da forma y estructura. Es transmitiendo ideología en una forma determinada, fijándola dentro de ciertos límites novelescos, como el arte es capaz de distanciarse de ella, revelándonos de este modo los límites de la ideología (1978, p. 37).

De esta manera, si bien se parte de elementos de una realidad cargada de ideología, por medio del procedimiento artístico también se puede cuestionarla y establecer los límites de su sustento. En esta dualidad es donde transcurre la obra artística: parte de la ideología dominante, para luego introducir un extrañamiento que visibiliza sus grietas. Vale la pena recalcar que esto no implica una negación absoluta de la realidad sociosimbólica, sino apenas traer nuevas percepciones a la realidad social gracias, en este caso particular, al progreso de la forma literaria, la cual estaría también redefiniendo las relaciones entre artista y público (Eagleton, 1978, p. 43), pero en un camino distinto a la relación establecida en la forma burguesa.

En un tono muy cercano al anterior teórico citado, las reflexiones del teórico cultural Fredric Jameson también ayudan para analizar las conexiones entre la producción narrativa y el contexto social. En Documentos de cultura, documentos de 
barbarie, uno de sus textos olvidados por la crítica literaria, el autor problematiza las relaciones que existe entre literatura y sociedad desde una óptica marxista, a partir del concepto de "mediación", que sería "el término dialéctico clásico para designar el establecimiento de relaciones entre, digamos, el análisis formal de una obra de arte y su base social, o entre la dinámica interna del estado político y su base económica" (Jameson, 1989, p. 33). De este modo, la investigación literaria no se limitaría simplemente a revisar la forma estructural que presenta, sino también habría que analizar los lazos que guarda de cara al marco social que introduce. Así, "el análisis de las mediaciones apunta a demostrar lo que no es evidente en la apariencia de las cosas, sino más bien en su realidad subyacente, a saber [sic] que en los lenguajes específicos de la cultura opera la misma esencia que en la organización de las relaciones de producción” (Jameson, 1989, p. 33). Es decir, hay un vínculo cercano que se teje entre ambos planos (si se puede traducir en el plano ficticio y el de la realidad) que sería el lenguaje.

Uno de los procedimientos que propone la forma literaria es el resquebrajamiento de la ideología que compone su estructura simbólica inicial. Con esto no se quiere afirmar que la ideología se encuentra fuera de la obra o que deforme a esta última, sino que el resultado del proceso artístico ya de por sí es un "acto ideológico", cuyo objetivo no sería más que plantear "soluciones" imaginarias o formales a contradicciones sociales irresolubles (Jameson, 1989, p. 64). De este modo, la ficción narrativa estaría sirviendo como velo aparente ante los problemas que se plantean en la realidad social, lejos de plantear respuestas inmediatas. Y es que la literatura consiste en la producción de una realidad, no autónoma, sino material, la cual estaría cargada de cierto efecto social (Balibar y Macherey, 1978, p. 38). Esta manifestación se constataría en la narrativa o forma literaria adoptada, dependiendo de la coyuntura político-social en la que surja la obra. Véase la siguiente cita, donde propongo leer "narrativa" cuando se mencione la palabra novela:

La tendencia política debe surgir discretamente de las situaciones dramatizadas; solo de esta manera indirecta podría una novela revolucionaria operar efectivamente sobre la consciencia burguesa de sus lectores. Una novela de base socialista logra completamente su propósito... si al describir concienzudamente las relaciones mutuas reales, derribando las ilusiones convencionales acerca de ellas, destruye el optimismo del mundo burgués, infunde duda sobre el carácter eterno del mismo, aunque el autor no ofrezca ninguna solución definitiva o incluso aunque no se alinee abiertamente en ningún lado determinado (Eagleton, 1978, p. 63). 
Para Terry Eagleton, la literatura puede generar un extrañamiento a la ideología burguesa por medio de la representación política que se filtra al interior del mundo representado en la ficción. De este modo, se estaría alterando los cánones contemporáneos con los que se juzga a una narrativa de "buena" o "mala", pese a que no se proponga una sola respuesta ante semejante problema. Así, la poética del autor quedará abierta a sus planteamientos ideológicos, lo cual se revelará en la narrativa adoptada. Para redondear y atraer a colación la estructura del cuento que se busca trabajar en este trabajo, Fredric Jameson, en un libro publicado recientemente, nos dice del cuento lo siguiente:

La función de contar cuentos, si queremos llamarla así, debe formar parte de una oposición, debe quedar definida contra otra cosa; de lo contrario, la potencialidad que estamos tratando de circunscribir corre el riesgo de extenderse a todo el campo de la actividad mental, convirtiéndose todo en narrativa, en un tipo de cuento (2018, p. 22).

En esta última cita se pueden notar las exigencias antinómicas que busca trabajar Jameson, puesto que indirectamente quiere plantear el problema del cuento a nivel de la contradicción, la cual a su vez está envuelta de ideología. Como se veía líneas atrás, la propuesta del lenguaje literario busca resolver aquello inconcluso en la realidad, pero en el caso del cuento, debe tomar posición inmediata, pues de lo contrario se podrá denominar cuento a cualquier estructura narrativa empleada. Visto así, y pese a que Jameson no lo mencione, se puede señalar que el papel del antagonismo también es relevante para construir un cuento, puesto que de ahí también depende la aparición de la contradicción. En las líneas que siguen, se analizará los cuentos del primer número de la revista Narración, poniendo énfasis en cómo se construye la ideología a través de la contradicción planteada, y cuáles son las problematizaciones ideológicas que cada cuento presenta.

\section{Los cuentos en el primer número de la revista Narración (1966)}

Los seis cuentos que componen el primer número de la revista se agrupan en el común denominador del realismo, con sus distintas vertientes posibles. Sin embargo, para detallar mejor el alcance de los cuentos, los organizaré por cuestiones temáticas, en una clave ligeramente distinta a la que plantearon Arámbulo y Valenzuela (2018). Coincido con ellos en la denominación de "realismo urbano" que emplean para la clasificación de algunos cuentos, pero disiento de la tipificación de "realismo mágico", "neoindigenismo" y "regionalismo" de la otra mitad de cuentos (Arámbulo y Valenzuela, 2018, p. 60). La razón de mi posición se basa en 
que estas tres vertientes pueden articularse en lo que se podría llamar "realismo popular", aquella modalidad narrativa que incluye las distintas sintaxis y sincretismos que pueden presentar las capas excluidas o que se tensionan con el mundo moderno. Por este motivo, en vez de organizar los cuentos según las divisiones narrativas tradicionales, el adjetivo popular permitirá matizar el papel que cumple el componente ideológico dentro de la propuesta marxista que abraza el proyecto de la revista.

Según la clasificación que propongo, en un primer momento, entonces, se mantendrían los cuentos "Perfil de traidor", "A la deriva", "Los kantus" y, a su modo, "La timba". Menciono esto último, pues se trata de una narración plagada de coloquialismo juvenil, lo cual también permitiría adscribirse al otro bloque. Por el otro lado, agrupados en lo que denominé "realismo popular", calzarían los cuentos "Muerte de Dimas", "Pichana" y "El trapiche". Esta diferenciación también se hará evidente en el contenido tratado en cada conjunto de cuentos, los cuales ponen en visibilidad la dimensión ideológica y política de los cuentos.

El cuento que abre la revista es "La timba", de Carlos Gallardo. En este se narra la experiencia de juego de unos adolescentes o jóvenes — no se sabe bien - ubicados en un inmueble deshabitado, por lo que se intuye. El narrador heterodiegético exalta las disposiciones corporales y sensitivas de los jóvenes que están jugando. El detalle puesto en la expresión corpórea remarca sus deseos por sentirse, de una vez por todas, hombres adultos. Este tipo de narrativa colinda con la propuesta desarrollada por Oswaldo Reynoso en Los inocentes, cuyos personajes dan cuenta de la dificultad de la formación masculina frente a una sociedad que se moviliza alrededor de la cultura autoritaria. Retornando al cuento, a nivel ideológico se puede decir que hay una primera correspondencia de parte de los jóvenes con el statu quo por medio del no cuestionamiento al lugar que ocupan dentro de la sociedad. Sin embargo, el extrañamiento de dicha base ideológica comienza cuando los cuerpos adoptan unas posturas que le son ajenas. Si a nivel discursivo los jóvenes se expresan con jergas o con un lenguaje callejero, el cuerpo representado en la narración revela cierta incomodidad de formar parte de la normativa ideológica:

Ahora jugaba Pelucas y sonreía de manera forzada, su rostro se cuarteaba con la excitación. Sus dedos de uñas negras parecían de hechicero cuando recogía y tiraba los dados. Temblaba. El cabello le caía sobre la frente y encima de las orejas hasta que no aguantó más; pasó los dados, se levantó, caminó a un lado y abrió las piernas para orinar (Gallardo, 2018, p. 4). 
Su disposición a adquirir las conductas de adultos se constata con la necesidad de cambiar fisiológicamente. La contradicción estaría, como se ve ahora, a nivel del lenguaje corporal, aunque no es necesariamente la única. Ya en los párrafos posteriores, se manifiesta la persecución policial sobre el grupo de jóvenes, lo que revela el antagonismo que representan para el orden social. La ideología dominante, representada por la institución policial, no da con el objetivo de su captura, puesto que uno de los jóvenes, apodado Diablillo, avisó de la inminente redada que les esperaba. La última lisura que uno de ellos profiere a la Policía cuando están en plena huida permite visibilizar la contradicción en el cuento: aquel estado de aparente tranquilidad y jolgorio fue interrumpido por las fuerzas del orden, en una escena donde sale a relucir las diferencias de clase. De un lado los jóvenes cuyas prácticas sociales no coinciden con el patrón del orden social; mientras del otro, el aparato policial que viene a controlar las reglas sociales de la clase dominante. En el plano ficcional, no se clarifica si fueron o no capturados los jóvenes, aunque sí se puede comprobar el fastidio que les ocasionó por medio del insulto con el que se cierra el cuento.

El segundo cuento se titula "Muerte de Dimas", de Eduardo González Viaña, quien solo colaboró en el primer número de la revista. En este texto se relata la creencia popular de que la muerte se personifica en la tierra para llevarse a los cadáveres, en este caso particular, a Dimas. El cuerpo de este se encuentra en una choza alejada del lugar donde se narran los hechos, por lo que se vuelve constante de parte del narrador en primera persona del plural de ir preguntando siempre a un tercero informante sobre el estado del cuerpo de Dimas, mientras se espera a que la muerte venga por él. Las reiterativas preguntas sobre la llegada de la muerte implican un temor hacia lo que esta podría realizar. Sin embargo, casi al final del cuento se da el aviso de que hay alguien más dentro de la choza donde se encontraba el cuerpo:

Fue al octavo día cuando alguien creyó escuchar algo. No se sabe si en las chácaras o en el río. No se sabe si un grito o un galope. Cuando aquel dijo que había oído un grito todos aseguramos que también lo habíamos oído y, sin mirarnos más, entramos a la casa con el machete en las manos y las antorchas encendidas (González, 2018, p. 5).

Si en un primer momento se tenía una incertidumbre por lo que le estaba pasando a Dimas — de ahí que se evite permanecer donde se encuentra su cuerpo-, al finalizar se rompe ese marco ideológico de sometimiento, para pasar a la acción y contraponer la violencia ante la posible presencia de la muerte, en lo que se podría 
llamar justicia retributiva. Así, el problema de la contradicción en el cuento, que está manifestándose en el deseo de justicia frente a la muerte, pasaría a resolverse mediante el homicidio de la encarnación de la muerte. Como en el cuento anterior, tampoco se puede afirmar que dicho acto se concrete, pues el desarrollo de las acciones queda en suspenso.

Los dos cuentos que siguen rondan la temática urbana, aunque, si bien coinciden en que abordan problemas de la subjetividad, presentan conflictos distintos. E1 primero de estos se titula "Perfil de traidor", de Miguel Gutiérrez. Este relato enfatiza la perspectiva del narrador en segunda persona, quien a la vez parece controlar las acciones del personaje principal, cuyo nombre no sabemos. El cuento presenta el estado psicológico de aquel, quien se encuentra en una situación de constante duda. La labor entregada a su persona consiste en redactar unas crónicas periodística, para la cual tiene que investigar y reportar sus avances ante su jefe Morales. La cuestión ideológica dentro del cuento se encuentra en la forma de afrontar los informes ante su superior. No son casuales las descripciones que realiza el narrador sobre cómo el personaje principal —denominado "gordo" en algún momento- llega a un bar con el fin de llamar por teléfono, aunque esta acción se dilata debido a que se pone a beber una cerveza. En este simple o trillado acto se puede visibilizar el estatuto social al que pertenece el "gordo", puesto que se van revelando sus prejuicios y visiones respecto al espacio social en el que se encuentra. Sin embargo, en una lectura superficial no se podría dar cuenta de dónde viene su desequilibrio psicológico, cuyas raíces causales se encontraría en su labor de investigación periodística:

Y ahora bebe sorbo a sorbo. Y piensa en ti, en tu vida, y sobre todo, en quien sospechas el causante de este malestar, en Monzón, Víctor Raúl Monzón, hijo del manco Monzón, quien no estuvo a la altura de su padre [...] y prefirió suicidarse (Gutiérrez, 2018, p. 7).

Vista así la situación, se entiende mejor que aquel "desequilibrio" de parte del "gordo" no es casual, sino que tiene relación con su pesquisa, la cual lo llevó a indagar sobre las causas del suicidio. Explícitamente no se detalla dónde surge aquella reacción psicológica, aunque se puede tener el beneficio de la duda de que partió de su encuentro con lo que en psicoanálisis se denomina lo "real traumático", aquella instancia cruda que es producto no de fuerzas externas al acto social, sino producto de las grietas simbólicas difícilmente de asimilar (Zizek, 2008, p. 80), por lo que permanecen algunas secuelas a nivel psíquico. Las implicancias de ese "malestar" respecto a la ideología son un poco contrarias a los dos 
cuentos analizados anteriormente, pero de igual forma revelan las contradicciones en la clase social representada: a saber, la pequeña burguesía. La resolución de la contradicción en este cuento no pasa por actuar y desasirse de la ideología, sino por comprender la inconsistencia de esta respecto a la clase que asume sus dictámenes. Es decir, el cuento no tiene la intención de explicitar el problema real; por el contrario, busca complejizarlo un grado más para que el lector reconstruya el texto y encuentre la fisura en el estrato ideológico. De este modo, más que de denuncia, el cuento permite constatar los límites de la ideología burguesa, a partir de la complejidad subjetiva del personaje principal.

El siguiente cuento se titula "A la deriva”, escrito por Andrés Maldonado. Aquí, la temática gira en torno a la incertidumbre de la vida de Alfredo, joven colegial de últimos años, quien no sabe qué hacer en un domingo cualquiera. Los dilemas de su clase — vale decir, la clase media — salen a flote, como son la congregación a las iglesias los fines de semana, los lazos amicales, entre otros. La cuestión ideológica aparentemente se encuentra ensamblada, aunque en ciertas escenas se deforma ese ambiente hospitalario mesocrático. Por ejemplo, cuando el cardenal de la iglesia menciona que "hay que tomar las armas" (Maldonado, 2018, p. 8), en clara sintonía con cierto sector clerical que respaldaba los postulados de la teoría de la liberación. La cuestión ideológica que se presenta en el texto tiene sus puntos de relieve al finalizar el cuento, cuando, en un acto de conmiseración, entrega 10 soles a un mendigo (Maldonado, 2018, p. 9). Esta "resolución” aparente no hace sino reforzar el estado de bienestar del sector social dominante sobre el más desfavorecido. Detrás de ese acto de regalar su dinero, Alfredo está reproduciendo la ideología y el eslogan capitalista de que siempre hay que "colaborar con los más necesitados". Aquel acto de desprendimiento de dinero, entonces, funciona perfectamente para mantener en equilibrio la base ideológica que cohesiona a la pequeña burguesía, en este caso, la clase social a donde pertenece Alfredo. Sin embargo, posteriormente se distorsionará esa coherencia ideológica para poner en evidencia el lugar que ocupan los personajes en la narración:

Unas cuadras más allá: el mercado. Del interior emanaba un olor hediondo a comestibles en descomposición. Alfredo recordó a su madre diciendo: "no se controla nada, las carnicerías venden al precio que quieren...”. Con higiene o sin higiene. Así es Huamanga. “...las verduras tiradas en el suelo y el Alcalde [sic] que nunca está en la ciudad sino dedicado a sus asuntos...”. Tiene más iglesias que curas. “... a su hacienda y qué sé yo, todo es una desgracia...”. Dos cuadras más abajo, llegó a la calle principal; estaba desierta y empolvada (Maldonado, 2018, p. 9). 
La representación del mercado pone en escena la vida popular, aunque a ese acto descriptivo se superponen las perspectivas de Alfredo y su madre, las cuales no marchan al mismo compás. Mientras que para Alfredo Huamanga es así como se muestra, para su madre no es lo mismo; ella demanda un orden ante el precio y la forma de ofertar los productos, para lo cual denuncia al alcalde, quien sería el causante de todo. Esto lleva a leer el factor ideológico que se camufla en cada perspectiva donde, por un lado, se comprende que el factor popular no distorsiona el orden social, mientras que, por el otro, se concibe al desorden y la falta de higiene como una situación crítica, donde la tranquilidad de la clase media se ve completamente afectada. El cuento posteriormente tomará el rumbo de la metaficción, puesto que Alfredo piensa escribir un cuento sobre lo que ha vivido ese día, el cual comienza justamente como este cuento que he analizado. Retomando el tema de la ideología, es posible señalar que todavía hay tensiones dentro del lugar que ocupa en Alfredo. Justamente al encontrarse en el sector de la pequeña burguesía, y desprendido de los problemas que sectores menos favorecidos pueden tener, visiona el mundo con comodidad, aunque pese a ello no sabe qué es lo que desea en su vida. Más que de crítica a la ideología burguesa, es un retrato del sector clasemediero y el intento por representar sus preocupaciones dentro de la creación ficcional, pese a que esta puede tomar una dirección contraria a lo leído en este cuento, si es que desglosa los problemas percibidos en su jornada cotidiana. Es incierto el final, aunque este concluye con una necesidad de "actuar" por medio del arte.

Para retomar el otro agrupamiento de cuentos, posteriormente viene el cuento "Pichana" de Juan Morillo. Acá resonará bastante el tema de la vida después de la muerte, como el cuento de González Viaña, pero con otras exploraciones psicológicas. El cuento relata la historia de Silverio y el recuerdo de su madre cuando pronuncia la palabra pichana (la cual significa, por lo que se colige del texto, "bruja[o]"), cuando estaba calificando a otra persona que le rogaba cobijarlo en su choza. Este acto del recuerdo comienza desde el inicio del cuento, por lo que desde ese instante se va a intercalar con narraciones breves de escenas donde Silverio evoca diálogos con su madre. Si desde un inicio, entonces, teníamos a dos antagonistas bien marcados, toda esa consistencia ideológica de disputa se desborona cuando él recuerda a su madre. Posteriormente, dicha persona que le suplicaba se esfuma, con lo que Silverio llora y recuerda mucho más su vivencia con su madre. Entre líneas, se puede afirmar que su madre era "pichana", aunque de todas maneras esa escena queda un poco difusa, debido principalmente al contrapunto de 
voces que intervienen en ese momento. La narración toma, en ese momento, una etapa inesperada, en la cual Silverio es apresado para realizar el servicio militar obligatorio (otra vez, la institución militar o policial aparece, para poner orden a nivel ideológico). Sin embargo, para poder salir de ahí, necesita compararse con un animal, a propósito de lo que iba recordando en el trayecto a la cárcel:

recuerda los rodeos en el día de San Bartolo: polvorientos rastrojos, interminables tropeles y bramidos, sudor y lazos en el air, terneros con las orejas sangrantes, el chasquido de los fierros calientes sobre la piel virgen de los toros. Silverio entra en la cárcel [...] "Los toros rompen cercos - piensa-, saltan grandes pircas, se vuelven a su querencia; toro no soy, pero para salir de aquí puedo más que los toros" (Morillo, 2018, p. 11).

En ese sentido, la vida y la festividad campestre le otorgará un referente simbólico para que Silverio pueda darse valor de fugarse de esa cárcel. Si quizás no hubiera existido esa contraposición, él hubiera aceptado la imposición recibida. La contradicción entre la práctica subordinante moderna y los deseos personales son resueltos por medio del imaginario popular. Pese a esto, el cuento no se resuelve ahí, sino que, debido a su fuga, llega a perder conciencia de la realidad. Sus recuerdos sobre su madre empiezan a inundar su pensamiento, hasta que llega al punto de suicidarse de una manera no consciente, luego de estar viviendo una realidad aparte, junto con su madre. De ahí que su mundo interior no puede ser visto por la gente que mira su cadáver, pues para uno de los hombres que lo observa "más que pichana, parece un conscripto correlón" (Morillo, 2018, p. 17). Si en un nivel superficial este cuento no parece revelar ninguna contradicción o historia relevante, a nivel ideológico podría mostrar la simplificación de la muerte. La causalidad queda "resuelta" cuando se certifica que es un soldado, mas no se cuestiona por qué o cómo llegó Silverio a ese punto. Este cuento podría inscribirse al grupo de temática urbano en el sentido que revela la indiferencia ante los muertos, pero debido a que los componentes narrados no conforman parte de ese espacio, propongo adscribirlo en el otro grupo. Incluso si se va un poco más allá con la interpretación, ese elemento desinteresado que es parte de la clase media, estaría entrando en funcionamiento en un ambiente andino, donde la dimensión subjetiva que anulada para dar con las explicaciones del caso.

El penúltimo cuento se titula "Los kantus", de Oswaldo Reynoso. Esta narración aborda la perspectiva de un niño ante la incertidumbre de las acciones de su padre, quien es perseguido constantemente porque apoya con las actividades del APRA. Esto se evidencia cuando el niño menciona que en los volantes hay un 
hombre con nariz de pájaro y con el puño levantado, lo cual hace clara mención a la figura de Víctor Raúl Haya de la Torre. El punto donde se tensiona la ideología para este niño es cuando su madre, debido a que vienen constantemente a buscarlo a su casa, lo fuerza a mentir para mantener la calma. Menciono esto porque la consistencia ideológica de un niño que va conociendo el mundo se da través de la verdad, pero en esta situación, donde se ve forzado a mentir, se puede resquebrajar ese orden apacible de la niñez. Esa transgresión ideológica impuesta al niño será una medida anticipatoria ante lo que vendría después, cuando los extorsionadores busquen desesperadamente a su padre dentro de la casa. Hasta allí, se vuelve evidente los dos bandos: de un lado los apristas, donde estaría Carlos Ramírez, el padre del niño, mientras que, del otro, se encontraría las fuerzas policiales al acecho, en busca de los militantes del APRA. El texto no establece claramente esto último, pero es posible intuir. En todo caso, podría ser agente contratados para perseguirlos. Sin embargo, a diferencia de las anteriores representaciones de la policía o militares, tenemos en escena un acto canalla de parte de estos últimos, pues en sus incursiones en busca de militantes de aquel partido, también aprovechaban en robar algunas cosas valiosas como un cenicero de su padre (Reynoso, 2018, p. 13). Sin embargo, esto no solo es lo curioso, sino que el cuento concluye cuando tanto la madre como el hijo minimizan el problema, incluso como si desde entonces estuvieran acostumbrados. Aquí surge una contradicción, debido a la reacción natural de parte de ambos personajes, a partir de dichos actos violentos que atraviesan. De este modo, el tipo de lectura que habría que ensayar aquí va por otro camino. La ideología que se va tensionando aquí es el uso de la violencia, tanto a nivel de la práctica política del padre, como la respuesta por parte de la Policía ante su imposibilidad de dar con su ubicación. Así, por lo que desprende ese final del cuento, la familia respaldó el actuar del padre a partir de entonces, pese incluso a la alteración de su tranquilidad de vida. De manera cautelosa, propone al lector que esa persecución policial no les intimida, porque debido a ello uno va ceder en sus proyectos políticos.

Finalmente, el cuento con el que se cierra la sección es de José Watanabe, llamado "El trapiche". En este se relata la vida de unos agricultores ante la presencia del trapiche, una máquina moderna que altera las relaciones sociales. Lo sustancial del cuento es que aborda la repercusión de este producto tecnológico, tanto a nivel del imaginario de los infantes, como también respecto al orden simbólico de los adultos. Si bien uno pensaría que con una máquina que acelera el proceso laboral todo sería más sencillo; sin embargo, para los trabajadores eso no 
sucede del todo. En un primer momento, surge la desconfianza ante este invento moderno, específicamente a partir del temor de los niños, quienes lo animalizan y lo comparan con un dragón. El miedo hacia esta máquina surge debido al ruido, aunque su salida imaginaria inmediata para suprimir esa sensación, se revela con su anhelo de destruirla cuando sean grandes, en una enunciación que - posteriormente se entenderá mejor - tiene una carga ideológica bien fuerte. Javier, padre de una familia y personaje principal de este cuento, tras la muerte de un colega suyo, pondrá en cuestionamiento las labores que realiza:

— ¿Cómo se va la gente, no? Hace un mes don Pancho y anteayer, mi compadre Pedro. Pobres.

-Fue un accidente con don Pancho, dicen.

-Sí, dicen que fue un accidente. Y Pedro tuberculoso. Mentiras. Fueron 15 años en la fábrica, en el trapiche. Los venció la madrugada y el trabajo duro. Todavía me acuerdo cuando entramos a trabajar. Creímos que era suerte porque en ese tiempo no había trabajo. Pero ya ves, ahora suerte es morirse.

- No hables así. Podemos ahorrar un poco y largarnos a otros sitio [sic].

-Ya no, lo único que he ganado es sentirme como que yo también estoy muerto. Pero puede ser. Quizás algún día nos podremos ir. En fin, yo estoy aquí para aguantar o por lo menos para tener cólera (Watanabe, 2018, p. 15).

Este diálogo entre Javier y Juana, su esposa, constata la explicación del primero sobre el fallecimiento de Pedro, lo cual fue ocasionado debido a las condiciones precarias donde ejercía su trabajo. Ella, por contraparte, trata de ser más abierta e incluso se muestra optimista de que pueden decidir el lugar donde podrían ir a vivir. De este modo, la ideología se pone en tela de juicio a partir de la mirada de Javier, por medio de una explicación más concreta de las condiciones materiales del trabajo, aunque luego él cede ante la posibilidad de instalarse en otro lugar. Cabe recordar que Javier sabe cuál es el efecto a largo plazo del trabajo en el trapiche y, pese a que no enuncia el tipo de muerte que tendrá, la forma en que sucederá su muerte se manifiesta en su sueño, en el cual la maquina "lo devoraba. No con un golpe seco, sino lentamente. Lentamente su sangre fortalecía y aceitaba las muelas del dragón. No con un golpe seco y rotundo, sino día a día, lentamente" 
(Watanabe, 2018). Así, inconscientemente Javier da consistencia a lo que le habría de ocurrir en un futuro. Esta descripción de su posible muerte simplemente cohesiona mejor el diálogo que tuvo con su pareja, en donde ya daba indicios de que su vida era como la de un muerto viviente, lo cual se corrobora con su deseo expresado en su sueño. Ahora bien, el cuento aparenta cerrar con este pasaje; sin embargo, retomemos lo que señalaban los niños, de que destruirían la maquina cuando fueran grandes. Esa expresión, se había dicho, está cargada de ideología, pues pese a que el deseo de acabar con el trapiche sea uno de tipo infantil, extendiendo la metáfora y el tiempo narrativo que no incluye el cuento, esa "muerte" (simbólica, añadiría yo) podría realizarse cuando esos niños tomen conciencia de la opresión laboral que produjo sobre sus padres. Por el momento, queda la rabia para resistir ante dicho abuso laboral. Este sentimiento podría abrir un horizonte de reclamo no solo personal, sino colectivo, pues ya existe un sindicato, el cual, incluso, podría llamar a una huelga por mejores condiciones laborales. De este modo, si por una parte el cuento concluye con Javier resignándose ante el imperativo ideológico de permanecer en el trabajo pese a las explotaciones que sufra, por otra parte, las palabras de los niños, aunque parezcan inocentes, podrían materializarse posteriormente y cerrar esa contradicción que subsiste en el cuento. No se menciona que Javier vaya a morir trabajando en el trapiche, ni que Miguel, su hijo, producto de esto, vaya a salir a pedir reclamar mejores derechos laborales, aunque hay cierta intuición de que eso ocurra, esto principalmente a que no se haya alterado las acciones al interior de cuento.

\section{Conclusiones}

Las derivas ideológicas de los sietes cuentos incluidos en el primer número de la revista Narración, más que adscribirse mecánica y panfletariamente a la propuesta marxista, buscan cuestionar y problematizar algunos presupuestos del conflicto entre clases sociales. Es decir, su necesidad estética no es la de representar solo el abuso del modo capitalista de producción, sino también la de evidenciar las reacciones ante la dominación ideológica en distintas situaciones y niveles sociales, vale decir, las formas de resolver las contradicciones planteadas en el texto. De este modo, cada cuento pone en evidencia la agencia por parte de los personajes antes que mostrarlos inmóviles, pero desde las particularidades que cada uno plantea al respecto: en "La timba", la fuga ante la persecución policial; en "Muerte de Dimas”, cometer un acto de venganza ante la personificación de la muerte; en "Perfil de traidor", el desequilibrio psíquico luego de indagar en un caso periodístico; en "A la deriva", el acto de escritura; en "Pichana", la muerte no-consciente 
de Silverio; en "Los kantus", la normalización de la requisa a la casa; y en "El trapiche", la aceptación de la explotación laboral. Sin embargo, como se ha visto en los análisis de cada cuento, la contradicción no queda resuelta con estos actos, sino que, gracias a una lectura ideológica, detrás de estos también se pueden observar los actos simbólicos que implican esas reacciones. Solo leyendo a través de ese lente se podrá tomar en consideración el movimiento que efectúan estas ficciones a nivel narrativo, las cuales parten de una realidad localizable, para apuntar luego a las implicancias de orden político que atraviesan dichas narrativas. Así, la lucha de clases que debe manifestarse en los cuentos queda reemplazada por el conflicto interclasista, en una salida un tanto estratégica para evitar el maniqueísmo narrativo. Por cuestiones de espacio, no se ha podido analizar en este trabajo los cuentos que componen los dos números restantes de la revista, por lo que queda abierta la continuación de este abordaje.

En la línea de la crítica literaria, la composición de los tres números de la revista fue analizada hace algunos años por Carlos Arámbulo y Jorge Valenzuela (2018), en un análisis que estudiaba separadamente las partes en que se subdividía la revista. La estrategia no está mal, pero deja de vista la sintaxis propia de la revista, es decir, la posición que ocupa cada texto en relación con el resto de las demás secciones y su intervención dentro coyuntura de la época (Sarlo, 1992, p. 12). En esta misma línea es posible investigar a Narración, para que, de ese modo, no solo se limiten los estudios a una sola sección — como se hizo en el presente artículo-, sino que también se pueda contrastar las formas de diagramación de la revista, o la organización de las secciones que componen el material, lo cual incluso podría fácilmente analizarse desde la teoría de la recepción. Este corte analítico, que parte especialmente del estudio de revistas, hubiera complementado algunos vacíos que los autores mencionados líneas atrás debieron tomar en cuenta, ya que las revistas son vistas como un producto con un lugar de confluencia para "la construcción de un lugar de enunciación y práctica para el intelectual comprometido" (Gilman, 2003, p. 79). Esa idea del intelectual comprometido la adoptarán distintos escritores durante los años 60 y 70, para quienes la política y el espacio público fueron el lugar de legitimación de sus producciones (Gilman, 2003, p. 29), de tal modo que se iba cuestionando los postulados del "arte por el arte” para ligarlos con procesos sociales. Sin embargo, para ahondar el análisis de una revista, habría que mirarla no como un conjunto de secciones intercaladas, sino como una revista vocera de un grupo que se propone "postular una agenda y desplegar una política cultural mediante una intervención en el campo intelectual 
que adopta la forma de un juego de disputas y alianzas con otras revistas por el reconocimiento, el prestigio y la legitimidad"(Tarcus, 2020, pp.33-34). Evidentemente, ese análisis pormenorizado de la revista Narración está pendiente todavía, aunque ya se han publicado testimonios de algunos de sus miembros, quienes han revelado los modos y lugares de circulación de la revista. Lo que todavía no se ha analizado con mucho cuidado es el proyecto editorial que nace con esta revista, como son las ediciones Narración y Nueva Crónica, donde publicarían algunos miembros. Del mismo modo, para un estudio más estimulante, cabría ponerla en diálogo con las demás revistas que circulan a fines de los años 60 e inicios de los 70. Las revistas de poesía de aquella época también tienen una carga ideológica contestataria bien marcada, por lo que los resultados de aquella persona que analice la red de revistas de dichas décadas otorgarán nuevas luces a las relaciones entre literatura y política, en un Perú donde la coyuntura política marcaba la pauta de los movimientos artísticos.

\section{Notas}

1 Detenerse en el análisis de aquellos dos soportes materiales trae de vuelta el marco histórico que últimamente se ha dejado de lado en los estudios literarios. Esto no implica pensar que la crítica literaria tornará en una acumulación de datos o que se utilizará la literatura para explicar los fenómenos sociales. Al contrario: se trata de dotar el elemento histórico-social que está, implícita o explícitamente, dentro del texto. Esta operación crítica permitirá conjugar los elementos que componen a la obra con su trasfondo ideológico-político, como explicaré más adelante.

2 Para comprender mejor los años 60, se puede comprender mejor la circulación de ideas de izquierda a nivel global y latinoamericano si seguimos el concepto de los "global sixties" (los 60 globales). Esta categoría, acuñada por el historiador Eric Zolov, permite pensar los contextos nacionales en clave transnacional, a partir de las contracorrientes geopolíticas, culturales e ideológicas cuyas consecuencias en distintas partes del mundo guardaron una similitud, lo cual sugiere una causa entrelazada (2018, p. 11).

\section{Contribución del autor}

Víctor Ramos Badillo ha participado en la elaboración, la compilación de datos, la redacción y el consentimiento de la versión final del presente artículo. 


\section{Fuente de financiamiento}

La investigación es autofinanciada.

\section{Conflictos de interés}

Ninguno.

\section{Trayectoria académica}

Víctor Ramos Badillo es maestrando en Sociología de la Cultura y Análisis Cultural por la Universidad Nacional de San Martín (Argentina) y egresado en Literatura por la Universidad Nacional Federico Villarreal. Ha participado en jornadas internacionales en Chile y Argentina, así como en el Perú. Ha colaborado con textos en la Revista de Crítica Literaria Latinoamericana, la revista A Contracorriente, entre otras. Se dedica a la docencia en educación superior.

\section{Referencias bibliográficas}

Arámbulo, C. y Valenzuela, J. (2018). Narración, cincuenta años después. Fondo Editorial de la Universidad Ricardo Palma.

Balibar, E. y Macherey, P. (1975). Sobre la literatura como forma ideológica. En J. Azpitarte (selec.), Para una critica del fetichismo literario (23-46). Akal Editor.

Eagleton, T. (1978). Literatura y crítica marxista. Zero.

Gallardo, C. (2018 [1966]). La timba. Narración, revista literaria peruana, (1), 4.

Gilman, C. (2003). Entre la pluma y el fusil. Debates y dilemas del escritor revolucionario en América Latina. Siglo XXI Editores Argentina.

Gonzáles, E. (2018 [1966]). Muerte de Dimas. Narración, revista literaria peruana, (1), 5 .

Gutiérrez, M. (2018 [1966]). Perfil de traidor. Narración, revista literaria peruana, (1), 6-7.

Jameson, F. (1989). Documentos de cultura, documentos de barbarie. La narrativa como acto socialmente simbólico. Visor.

Jameson, F. (2018). Las antinomias del realismo. Akal.

Maldonado, A. (2018 [1966]). A la deriva. Narración, revista literaria peruana, (1), 8-9. 
Morillo, J. (2018 [1966]). Pichana. Narración, revista literaria peruana, (1), 5.

Reyes, R. (2018). Narración: cincuenta y dos años después. Pacarina del Sur, 10(37). http://pacarinadelsur.com/home/huellas-y-voces/1686-narracion-cincuenta-y-dos-anos-despues

Reynoso, O. (2018 [1966]). Los kantus. Narración, revista literaria peruana, (1), 5.

Sarlo, B. (1992). Intelectuales y revistas: razones de una práctica. América: Cahiers du CRICCAL, (9-10), 9-16.

Tarcus, H. (2020). Las revistas culturales latinoamericanas: giro material, tramas intelectuales y redes revisteriles. Tren en Movimiento.

Valenzuela, J. (1989). El grupo Narración. Análisis de una experiencia literaria en el proceso de la narrativa peruana. [Tesis de licenciatura, Universidad Nacional Mayor de San Marcos].

Watanabe, J. (2018 [1966]). El trapiche. Narración, revista literaria peruana, (1), 5.

Zizek, S. (2008). Cómo leer a Lacan. Paidós.

Zolov, E. (2018). Los 60 fueron globales. Lento, (62), 9-18. 